\title{
Causal inference, mechanisms, and the Semmelweis case
}

\author{
Raphael Scholl* \\ University of Bern \\ History and Philosophy of Science \\ Institute of Philosophy \\ Länggassstr. 49a \\ CH-3012 Bern \\ Switzerland
}

May 10, 2012

The final publication is available at Studies in History and Philosophy of Science Part A.

*e-mail: raphael.scholl@philo.unibe.ch 


\begin{abstract}
Semmelweis's discovery of the cause of puerperal fever around the middle of the 19th century counts among the paradigm cases of scientific discovery. For several decades, philosophers of science have used the episode to illustrate, appraise and compare views of proper scientific methodology.

Here I argue that the episode can be profitably reexamined in light of two cognate notions: causal reasoning and mechanisms. Semmelweis used several causal reasoning strategies both to support his own and to reject competing hypotheses. However, these strategies have gone unappreciated in the existing literature. I show that a causal reasoning approach makes sense of the multitude of tables in Semmelweis's main text, which in later editions were often abridged because they appeared redundant.

Moreoever, the existing literature tends to focus on Semmelweis's clinical intervention and on the extent to which it alone confirms his theoretical conclusions. This neglects Semmelweis's efforts to show by animal experiments that his clinical results are in agreement with a demonstrable mechanism of puerperal fever pathogenesis. I argue that the full evidential force of Semmelweis's argument can only be appreciated if both his clinical and his laboratory investigations are taken into account.
\end{abstract}

\title{
1 Introduction
}

Ignaz Semmelweis's discovery of the cause of childbed (or puerperal) fever in the middle of the 19th century has come to play a double role in the history and philosophy of science. On the one hand, the episode is of intrinsic interest to historians of science and medicine because it contributed to a major transformation of our understanding of infectious diseases and their management. On the other hand, in philosophy of science the episode has assumed broader relevance due to its use as a case study of scientific discovery and confirmation. Philosophers have referred to it for decades in order to illustrate, appraise and compare methodological proposals.

The medical historian Erna Lesky (1964) already discussed aspects of Semmelweis's methodology at some length in the broader context of the Vienna Medical School of the 19th century. But Semmelweis's career as a methodological case study began in earnest with Carl G. Hempel's Philosophy of Natural Science (1966), in which Hempel used the Semmelweis case as a "simple illustration" of the hypothetico-deductive method. ${ }^{1}$ Only recently, Donald Gillies (2005) added

${ }^{1}$ Hempel (1966), pp. 3-18. 
a Kuhnian perspective to the Hempelian reconstruction. Among the most prominent critiques of the hypothetico-deductive account is Peter Lipton's seminal Inference to the Best Explanation (2004). Lipton argued for the superior philosophical virtues of inference to the best explanation explicitly by contrasting his account of the Semmelweis case with Hempel's. ${ }^{2}$ Current proponents of inference to the best explanation still use the Semmelweis case by way of illustration and argument. For instance, Alexander Bird (2010) has argued that the case constitutes a particular subtype of inference to the best explanation which he calls "inference to the only explanation", or "Holmesian induction". It speaks to the importance of the Semmelweis case in philosophy that the most widely used English translation of Semmelweis's main work, The Etiology, Concept, and Prophylaxis of Childbed Fever (originally published in 1861), was edited not by a historian, but by the philosopher K. Codell Carter. ${ }^{3}$ Among Carter's motivations for producing a new translation was his need of an accessible, yet substantial historical case study in a course in history and philosophy of science. ${ }^{4}$ It is thus no exaggeration to say that Semmelweis's work has become a paradigm case of scientific discovery and confirmation within philosophy of science.

In the present paper I am putting forward a new account of Semmelweis's methodology based on the cognate notions of causal reasoning and mechanisms. First, I will argue that Semmelweis's work can be reconstructed straightforwardly as a series of causal inferences along the lines of Mill's four methods (see section 2). Semmelweis's causal reasoning strategies have so far not been recognized as a coherent whole. I will argue that a major reason for this neglect is that Semmelweis's presentation in the Etiology relies heavily on numerical tables, which have traditionally received little notice except for their number and apparent redundancy. Many editions - including Carter's translation - omit most of the tables.

Next, I will argue that the philosophical discussion has been too narrowly focused on Semmelweis's clinical investigations and on the extent to which they alone confirmed his causal hypothesis (section 3). A reconsideration of the earliest published accounts of the discovery, as well as of Semmelweis's main work, suggests that the actual historical debate placed considerable importance on demon-

\footnotetext{
${ }^{2}$ Lipton (2004), pp. 74-90; first edition in 1991.

${ }^{3}$ In the present paper, references to Semmelweis's Etiology will be given for two editions: The original German edition (Semmelweis, 1861) and the English translation by K. Codell Carter (Semmelweis, 1983).

${ }^{4}$ See the translator's preface in Semmelweis (1983), p. ix.
} 
strating by animal experiments that Semmelweis's causal hypothesis was mechanistically plausible.

\section{A causal inference account of Semmelweis's work}

As a framework for reconstructing Semmelweis's causal inferences, I am going to use John Stuart Mill's four methods of experimental inquiry. ${ }^{5}$ The appeal of Mill's methods is that they are roughly contemporaneous with Semmelweis's investigations. Thus, an analysis of Semmelweis's work in terms of Mill's methods can be carried out free of the charge of anachronism.

However, two caveats are in order, one historical and the other philosophical. First, on the historical side, I am not suggesting that Semmelweis was directly influenced by Mill. My two claims are (1) that Mill successfully outlined at least some methods of causal reasoning that were used in 19th century empirical science, and (2) that Semmelweis used the same or similar methods. Where Semmelweis learned such methods is a different question. Erna Lesky traced Semmelweis's methodological influences through his teacher and supporter Joseph Skoda to the "numerical method" as advocated by the Parisian clinicians Pierre-CharlesAlexandre Louis and, later, Gabriel Andral. ${ }^{6}$ This is certainly plausible, although more recent work shows that the use of numerical methods was widespread in the early 19th century even before the Parisian pioneers, especially in Great Britain. ${ }^{7}$ For our present purposes, we can leave the question of intellectual influences aside. Thus, when I speak of Semmelweis using "Mill's methods", the claim is not of historical influence but of methodological affinity.

Second, on the philosophical side, I am not offering Mill's methods as a complete and workable apparatus for causal inference. Nor am I suggesting that an appropriately sophisticated modern theory of causal inference should replace all other approaches in confirmation theory. Hempel and Lipton proposed their reconstructions of Semmelweis's work as potential exemplars for all confirmation in science. My argument is initially local and historical: I will show that Semmelweis's methodology is best construed along the lines of Mill's methods. A discussion of

\footnotetext{
${ }^{5}$ Mill (1843), III.VIII.

${ }^{6}$ The claim is in Lesky (1964), p. 60. See also Roy Porter (1999), ch. 11, for an historical overview of the period, and Terence D. Murphy (1981) for a more extended discussion of numerical methods in early 19th century France.

${ }^{7}$ See Tröhler (2000).
} 
the relationship between Mill's methods and an overall theory of confirmation must be deferred to another occasion.

Let us now turn to the core historical argument. Among Mill's methods of causal inquiry are the method of agreement, the method of concomitant variation, and the method of difference. I will show that Semmelweis's data and arguments align neatly with these methods. ${ }^{8}$

\subsection{The Method of Agreement}

Semmelweis worked as a gynecologist and obstetrician in the city of Vienna between the years 1846 and 1849. Vienna's maternity hospital had two divisions at the time. In the first division, childbed fever caused the death of $10 \%$ of newly delivered mothers on average, but with monthly variation reaching as high as 30\% and as low as $1-2 \%$. The disease's main symptom was a high fever occurring hours to days after delivery (hence the name "childbed" fever); the underlying septicaemia, which caused the fever, frequently led to the patient's death. In the second division, childbed fever occurred as well, but at a strikingly lower average rate of little more than $3 \% .{ }^{9}$ No doubt the existence of two divisions with contrasting mortalities is a didactic virtue which goes far in explaining the case study's popularity.

Semmelweis's scientific achievement was to show that the causal pathway leading to the higher incidence of childbed fever in the first division was the following: Doctors and medical students transported some sort of disease-inducing agent from autopsies, which were performed nearby, to the pregnant women they examined. The outbreaks of childbed fever were confined to the first division because the second division only trained midwives, who, unlike doctors, did not perform autopsies. Semmelweis initially believed the disease-inducing agent to be cadaverous matter. Later, he started to think that other types of diseased or decaying substances

\footnotetext{
${ }^{8}$ In the interest of brevity and focus, I will only discuss the more prominent applications of Mill's methods in Semmelweis's work, and in particular the methods that are relevant to interpreting the numerical tables in the Etiology. Thus, I am here not discussing Mill's "joint application of the methods of agreement and difference". I am also foregoing a discussion of the "method of residues", although a strong case can be made that Semmelweis uses the method - specifically, when he concludes that there must exist additional causes of childbed fever since the introduction of cadaverous matter cannot account for all cases (see Semmelweis, 1861, pp. 133-34, or Semmelweis, 1983, p. 93).

${ }^{9}$ The numbers are from Semmelweis's first and third tables in the Etiology (Semmelweis, 1861, p. 3 and 13, or Semmelweis, 1983, p. 64 and 72). Semmelweis was not the first to note the striking difference in mortality rates between the two divisions: Eduard Lumpe, who had also worked at the Viennese maternity hospital and who later became one of Semmelweis's critics, noted in a text published in 1845 that the mortality in the first division sometimes exceeded that of the second division by a factor of four or five (Lumpe, 1845, p. 347).
} 
- such as pus - could also cause the disease. Today, of course, we understand the bacterial origin of postpartum sepsis. But regardless of the precise nature of the disease-inducing agent, the institution of hand-washing measures for all doctors and students succeeded in reducing the incidence of the disease in division 1 to the same level as observed in division 2.

The typical account of Semmelweis's discovery begins by enumerating a number of competing hypotheses concerning the pathogenesis of childbed fever which were current in the 1840s, and which Semmelweis had to refute. Let us begin with the notion that childbed fever was caused by some sort of "atmospheric influence". 10

The atmospheric hypothesis is usually taken to be in obvious contradiction with "well-established facts" (so writes Hempel, p. 3), and hence easily refuted by modus tollens: One would expect atmospheric conditions to have equal influence not only on both divisions of the maternity ward, but also on all parts of the city of Vienna - but this was clearly not, in fact, the case, and so atmospheric conditions could be disregarded. This brief summary reflects aspects of Semmelweis's reasoning in his text, but it is incomplete. Semmelweis did not regard this argument as conclusive, and presumably, his contemporaries would have agreed: It is after all possible that atmospheric influences are key to the pathogenesis of childbed fever, but that they only exert their effect under particular local conditions. And indeed this position was defended in textbooks at the time. ${ }^{11}$

What the existing literature fails to consider are Semmelweis's efforts to demonstrate numerically that atmospheric conditions are not linked to increases or decreases in the incidence of childbed fever. For this purpose Semmelweis used something along the lines of Mill's "method of agreement". Let us consider the method and Semmelweis's application of it in some detail. Mill defines the method of agreement as follows:

\footnotetext{
${ }^{10}$ Semmelweis uses "atmospheric influences" and "epidemic influences" roughly interchangeably: "By epidemic influences one understands atmospheric-cosmic-terrestrial changes, as yet not precisely defined, that often extend over whole countrysides, and by which childbed fever is generated in persons predisposed by the puerperal state" (Semmelweis, 1861, p. 4, or Semmelweis, 1983, p. 65).

${ }^{11}$ Note for example that the above mentioned Lumpe (footnote 9, ibid.) discussed the possibility that childbed fever is caused by a combination of general epidemic and local miasmatic influences. Far from rejecting epidemic factors as a candidate cause of childbed fever on the grounds that they would have to affect both divisions of the hospital equally, Lumpe took the different mortalities between the divisions as proof of the power of local miasmatic influences as causal co-factors. This reflects the general difficulty of falsifying causal hypotheses, since it is always possible to argue that the alleged falsifying instance simply lacked some relevant co-factor. For a discussion of this problem, see Nickelsen and Graßhoff (2011).
} 
If two or more instances of the phenomenon under investigation have only one circumstance in common, the circumstance in which alone all the instances agree, is the cause (or effect) of the given phenomenon. ${ }^{12}$

The purpose of Mill's initially forbidding terminology is epistemic: He needs to distinguish potential or candidate causes ("circumstances") and candidate effects ("phenomena") from actual, established causes and effects. By "instances" Mill refers to occurrences (and non-occurrences) of the effect under investigation which can be individuated in some way, and among which regularities can be ascertained.

Mill offers a more succinct version of the method of agreement two pages later:

The Method of Agreement stands on the ground that whatever can be eliminated, is not connected with the phenomenon by any law. ${ }^{13}$

It is this basic notion that Semmelweis applies to the question of atmospheric influences on the incidence of childbed fever. He writes:

If so-called childbed fever epidemics were really due to atmospheric influences, then they could not occur in opposing seasons and climates. In actual fact, however, the disease is observed in all seasons, in the most different climates, and under all weather conditions. ${ }^{14}$

In other words, Semmelweis argues that there is no agreement among the atmospheric conditions that predominate during outbreaks of childbed fever. Or to put it in yet a different way, he argues that time of year "can be eliminated" and is therefore "not connected with the phenomenon by any law".

We get an indication of how much weight Semmelweis attached to this argument from the fact that he devoted a page-long table to it, which is here reprinted as figure $1 .{ }^{15}$ For the years from 1841 to 1847 , the table shows both the highest and the lowest mortality rate recorded in any given month - thus, for example, mortality was lowest for the month of January in the year 1847 at $3.21 \%$ and highest in the year 1842 at $20.84 \%$. Semmelweis concludes:

\footnotetext{
${ }^{12}$ Mill (1843), p. 454; III.VIII.\$1.

${ }^{13}$ Mill (1843), p. 456; III.VIII.\$3.

14 "Wenn die sogenannten Kindbettfieber-Epidemien wirklich durch atmosphärische Einflüsse bedingt wären, so könnten sie nicht in den entgegengesetzten Jahreszeiten und Klimaten vorkommen; in der Wirklichkeit aber werden zu allen Jahreszeiten, in den verschiedensten Klimaten, unter allen Arten der Witterungsverhältnisse Kindbettfieber-Epidemien beobachtet" (Semmelweis, 1861, p. 7, or Semmelweis, 1983, p. 67).

${ }^{15}$ The table is also found in all editions and translations I am aware of. See for example Carter's rearranged version on p. 68 .
} 
This will prove numerically that every month of the year has presented both favorable and unfavorable states of health of patients in the first clinic. ${ }^{16}$

Thus, the method of agreement illuminates the causal reasoning underlying Semmelweis's numerical demonstration centered around his second table.

[Figure 1 around here.]

Mill discusses specific weaknesses of the method of agreement. First, the finding that all instances of a phenomenon $\mathrm{P}$ agree in the presence of a certain circumstance $\mathrm{C}$ suggests a causal connection, but not a specific causal structure. As Mill stresses in his definition (here quoted on page 6), the arrow of causation may point in the opposite direction: P may well be a cause of C. Or alternatively (if we allow for the existence of circumstances of which we are ignorant), $\mathrm{P}$ and $\mathrm{C}$ may be causally linked only indirectly through a common cause. Thus, the method of agreement does not permit us to establish the direction of causality, or to distinguish direct causation from epiphenomenal linkage.

Second, the method of agreement is unreliable in even minimally complex causal structures which include alternative causes. ${ }^{17}$ If we assume that a phenomenon $\mathrm{P}$ is caused by either $\mathrm{A}$ or $\mathrm{B}$, then the method of agreement would force us to conclude that neither A nor B is a cause (or effect) of the phenomenon, since A-caused and B-caused instances of $\mathrm{P}$ need have neither A nor B in common. Or in other words, we may exclude A and still observe $\mathrm{P}$, since it can also be caused by $\mathrm{B}$, and conversely. So if we assume that there are multiple constellations of causal factors that can produce childbed fever, then the method of agreement may lead us astray.

Mill writes that only the method of difference allows secure inferences. But this does not diminish the method of agreement's value:

\footnotetext{
16 "Es wird dadurch mittelst Zahlen bewiesen, dass jeder Monat im Jahre einen günstigen und jeder Monat im Jahre einen ungünstigen Gesundheitszustand der Wöchnerinnen an der ersten Klinik dargeboten hat" (Semmelweis, 1861, p. 7). The translation is mine, from Semmelweis's original. Although I generally tried to adhere to Carter's translation (Semmelweis, 1983, p. 67), in this case multiple imprecisions needed to be adressed. In Carter's translation, Semmelweis is supposed to say that "every month of the year can be either favorable or unfavorable for the health of patients", which implies a causal role for the time of year, although a variable one. But the verb Semmelweis uses is "darbieten", or "to present": Every month has presented both favorable and unfavorable statistics, and thus, on the method of agreement, we may exclude time of year as a potential cause. A causal connection is just what Semmelweis is denying. Moreover, Carter omitted the adverb "numerically", which wrongly deemphasizes Semmelweis's quantitative mindset.

${ }^{17}$ Mill (1843), p. 507; III.X.\$2.
} 
The Method of Agreement is chiefly to be resorted to, as a means of suggesting applications of the Method of Difference [...] or as an inferior resource, in case the Method of Difference is impracticable; which, as we before showed, generally arises from the impossibility of artificially producing the phenomena. ${ }^{18}$

Thus, despite the method of agreement's limitations, the method has heuristic value (as a guide for the application of the method of difference) and may serve as a limited tool (where the more robust method of difference is not applicable).

Before I turn to the method of difference, I will discuss how Semmelweis tested another competing hypothesis using the method of concomitant variation. This is by far the least understood part of Semmelweis's famous Etiology.

\subsection{The Method of Concomitant Variation}

Semmelweis's extensive use of numerical tables is a conspicuous feature of the Etiology. Curiously, many or even most of the tables are missing in some of the most widely available editions of the work. In general, editors and translators have taken the omitted tables to be redundant. For example, Paul Zweifel noted in the preface to a widely available German-language edition from 1912 that he had left out "statistical tables, which are for the most part unnecessary". ${ }^{19}$ Similarly, K. Codell Carter omitted ten tables from Semmelweis's main discussion in his widely used English translation (published in 1983) by noting that "Semmelweis gives eighteen pages of further tables presenting this information in different arrangements". ${ }^{20}$ While Carter is less dismissive than Zweifel, he also suggests that the tables are redundant. Already in 1964 Erna Lesky was dismayed that commentators had "at most expressed irritation at the abundance of [Semmelweis's] comparative tables of mortality and morbidity" without asking how Semmelweis came to employ such statistical methods. ${ }^{21}$ As mentioned above, I will not pursue the question of Semmelweis's intellectual influences. But Lesky is right to draw our attention to Semmelweis's neglected tables. ${ }^{22}$

\footnotetext{
${ }^{18}$ Mill (1843), p. 459-460; III.VIII.§3.

19“'Sein grundlegendes Werk, das hier zum Abdruck kommt, allerdings mit einigen Kürzungen, nämlich unter Weglassen von statistischen Tabellen, die für die Hauptsache entbehrlich sind, erschien erst im Jahr 1861" (Zweifel, 1912, p. 4).

${ }^{20}$ Semmelweis (1983), p. 70.

${ }^{21}$ Lesky (1964), p. 60.

${ }^{22}$ While the tables have not received the methodological analysis they deserve, they are intact in some important editions of the Etiology. See for example Semmelweis's collected works by Tiberius von Győry (1905) and the first English translation by Frank P. Murphy (Semmelweis, 1941).
} 
My thesis is that many of Semmelweis's tables only make sense if they are read in the context of causal reasoning strategies. On this view, it is no surprise that the tables have been misunderstood as redundant or as mere rearrangements of data, since the causal reasoning strategies underlying them have also gone unappreciated.

We have already seen that Semmelweis's second table can be understood as an application of Mill's method of agreement. In the present section I will discuss Semmelweis's tables four to thirteen, which were omitted by both Carter and Zweifel. All of these tables are best understood as applications of something like Mill's method of concomitant variation. Mill defines the method as follows:

Whatever phenomenon varies in any manner whenever another phenomenon varies in some particular manner, is either a cause or an effect of that phenomenon, or is connected with it through some fact of causation. $^{23}$

Semmelweis used the method of concomitant variation to test the hypothesis that overcrowding in the hospital wards is a cause of childbed fever. Again there exists a "shorthand" version that one finds in later accounts of Semmelweis's discovery: It is claimed that the second division was, if anything, more crowded than the first - and so another competing hypothesis was delivered a quick death by modus tollens. Again the claim is historically accurate: Semmelweis does point out that the first division had become notorious for its high mortality rate, so that patients maneuvered to be admitted to the second division, which consequently experienced more crowding. ${ }^{24}$

Again, however, Semmelweis's extended discussion is more sophisticated and quantitative, and it relies less than is commonly thought on comparisons with the second division. Over the span of ten tables, Semmelweis argues that crowding and mortality rate in the first division do not vary concomitantly. I suggest that we should take seriously the amount of space and typographical effort that Semmelweis invests in an argument: He would presumably not have devoted a table, let alone ten, to supporting an argument that he did not consider to be a pivotal one. However, the abundance of tables is not matched by an abundance of explanatory comments, so that the significance of Semmelweis's numbers is not immediately obvious from reading the text. This may explain in part why Semmelweis's editors generally chose to omit the tables.

\footnotetext{
${ }^{23}$ Mill (1843), p. 470; III.VIII.§6.

${ }^{24}$ Semmelweis (1861), p. 11, or Semmelweis (1983), pp. 69-70.
} 
The argument begins with the third table. Since no records of crowding were kept, Semmelweis uses the number of births in a given month as a proxy indicator. The table shows the number of births, the number of deaths, and (calculated from the first two) the relative mortality for every month from January 1841 to May 1847 (the point at which Semmelweis instituted his hand-washing measures, to be discussed below). ${ }^{25}$ Carter is correct in pointing out that the next ten tables are rearrangements of the data in the third table - but this view misses the methodological point.

In table four (see figure 2), Semmelweis uses January 1846 as the baseline, since it is the month with the greatest overall number of births (336 in total) and hence the greatest crowding. He then adds 13 months in which the total number of deaths remains above the baseline as the total number of births (and thus crowding) decreases from the maximum of 336 to as low as 209.

[Figure 2 around here.]

The fifth table (here not printed) continues the same argument by taking into consideration a further 11 months in which absolute mortality was below the January 1846 baseline of 45 deaths, but relative mortality was above the baseline of $13.39 \%$. Semmelweis tabulates a total of 24 months out of 76 in which crowding was lower but relative mortality was higher than during the month of maximum crowding. Thus, Semmelweis demonstrates that crowding and mortality do not vary concomitantly.

It is difficult from a modern vantage point to understand why Semmelweis did not present this information in the form of a graph, which would have made the underlying methodology much easier to grasp. Figure 3 is my own graphical representation of Semmelweis's data: It is easy to see - almost at a glance - that crowding and mortality do not vary concomitantly. Historians of the development of graphical methods regard the early 19th century as a time of innovation in which many graphical forms of representation were invented or improved (this includes bar charts, pie charts and histograms). ${ }^{26}$ The second half of the 19th century is considered a golden age during which enthusiastic use was made of the new graphical methods. However, the widespread adoption of graphical methods was not immediate. According to Funkhouser (1937, p. 292), even the question of whether numerical tables were preferable to verbal descriptions was disputed well into the

\footnotetext{
${ }^{25}$ This table is omitted by Zweifel (1912), but included in Semmelweis (1983) on p. 72. See the tables on p. 13 and following in Semmelweis (1861).

${ }^{26}$ See especially Funkhouser (1937) and Friendly (2008).
} 
19th century, and so it may not surprise that graphical representations were seen as even more problematic. Especially in England, statistical publications in the first half of the 19th century for the most part took tabular form (p. 293). Funkhouser quotes French and German commentators who, throughout the first half of the 19th century, expressed the opinion that graphs were mere playthings (p. 295). Friendly (2008, p. 13) notes that English statisticians were more inclined towards tables until as late as 1870 . Thus, while we lack a detailed history of the adoption of graphical methods by discipline and geographic region, the histories we do have suggest that it was not unusual for Semmelweis to present statistical information in tabular rather than graphical form. Moreover, my own analysis of the data in figure 3 is helped enormously by the use of linear regression, which suggests that the highly variable data series in the lower panel does not include a downward trend. However, linear regression was not available to Semmelweis. He may thus have concluded that merely plotting the data would not help him make his case.

[Figure 3 around here.]

What is the purpose of the remaining omitted tables? In tables six to ten, Semmelweis proceeds to consider a complex causal situation. The time of year and crowding may be interacting causal factors: For example, crowding may have a significant impact on childbed fever during the winter months. Semmelweis tries to tease these variables apart by considering each month separately (as an example, see figure 4). Printing just a subset of the data in table six, he notes that in the months of March and April the highest absolute number of births and the highest absolute number of deaths do in fact occur together (in the years 1846 and 1847, respectively). However, when relative mortalities are considered in table seven, Semmelweis notes that for any given month, the greatest relative mortality never occurred in the same month as the greatest number of births.

[Figure 4 around here.]

Tables eight, nine and ten are in the service of the same argument. But whereas tables six and seven only considered a subset of the 76 months for which Semmelweis has data, tables eight to ten tabulate all 76 months. Within each month, the years are arranged by number of births in table eight, by number of deaths in table nine, and by relative mortality in table ten. In his all-too-brief introductions for these tables, Semmelweis quite explicitly invokes a notion akin to concomitance of variation:

If, however, we arrange the individual months according to the number of births occurring in them, that is, according to the degree of crowd- 
ing, then a gradual decrease in the number of births, that is, in the degree of crowding, is not accompanied by a corresponding decrease in mortality [...]. If, however, we arrange the individual months according to absolute mortality, we see no corresponding gradual decrease in the number of births, that is, no corresponding gradual decrease in crowding [...] If, however, we arrange the individual months according to relative mortality, we see no corresponding gradual decrease in the number of births, that is, no gradual decrease in crowding. ${ }^{27}$

Thus, not only is Semmelweis here using the method of concomitant variation, he is also considering complex causal structures in a way that the modern literature on Semmelweis neglects to discuss.

Semmelweis then proceeds to the most straightforward application of the method of concomitant variation discussed so far. He arranges all 76 months according to the number of births (table eleven), the number of deaths (table twelve), and relative mortality (table thirteen). For each table, he notes (as above) that there is no concomitant variation between the variable according to which the table is arranged and the two remaining variables. See figure 5, which shows an excerpt from Semmelweis's eleventh table.

[Figure 5 around here.]

Again Mill discusses strengths and weaknesses of the method. The method of concomitant variation, much like the method of agreement, can suggest a causal relationship, but it cannot determine the direction of the causal arrow or exclude the possibility of a common cause. Nevertheless, like the method of agreement, the method of concomitant variation has considerable value. First, it can guide us to causal relationships that we may wish to investigate further by the method of difference. Second, in cases where we may not be able to apply the method of difference, the method of concomitant variation may be among our next best tools. Third, Mill particularly stresses cases where we cannot eliminate a variable entirely (for example, temperature) to test its causal relevance - but we may still observe its

\footnotetext{
27 "Wenn wir aber die einzelnen Monate nach der Anzahl der in derselben vorkommenden Geburten, d.h. nach den Graden der vorhandenen Ueberfüllung, aneinanderreihen, so zeigt sich bei der allmäligen Abnahme der Geburten, d.h. der allmäligen Abnahme der Ueberfüllung, keine entsprechende Abnahme in der Sterblichkeit [... ]. Wenn wir aber die einzelnen Monate nach der absoluten Sterblichkeit aneinanderreihen, so zeigt sich keine dem entsprechende allmälige Abnahme der Geburten, also Abnahme der Ueberfüllung [... ] Wenn wir aber die einzelnen Monate nach der relativen Sterblichkeit aneinanderreihen, so zeigt sich der allmäligen Abnahme der relativen Sterblichkeit keine allmälig entsprechende Abnahme in der Anzahl der vorgekommenen Geburten, oder keine allmälige Abnahme der Ueberfüllung [...]" (Semmelweis, 1861, pp. 18-26). The translation is my own, since the relevant section was omitted from Carter's translation.
} 
magnitudes to co-vary (with or without intervention) with another variable. Finally, after successfully demonstrating a causal relationship between variables $\mathrm{C}$ and $\mathrm{E}$ by the method of difference, we may profitably employ the method of concomitant variation to establish the precise quantitative relationship between the variables.

The causal inferences sanctioned by the method of concomitant variation are more limited if - as in this case - we find an absence of concomitance. Mill writes that "it is for the most part true that a modification of the cause is followed by a modification of the effect", but that this may not always be the case. ${ }^{28}$ A plausible causal structure to illustrate this is one where a threshold effect operates: An effect may occur when a cause of a certain magnitude is present, but the effect may then remain unchanged as the magnitude of the cause increases further. Hence, while concomitance of variation suggests causality, the absence of concomitance does not give equally strong evidence of the absence of causality. ${ }^{29}$ It appears that Semmelweis did not make this careful distinction. ${ }^{30}$

In summary, Semmelweis argues against the notion that overcrowding is to blame for childbed fever by demonstrating that changes in crowding are not accompanied by changes in mortality, and vice versa. The underlying logic is Mill's method of concomitant variation. This explains why Semmelweis included so many tables in his work, and their apparent redundancy vanishes (or is at least seriously reduced) once we understand the underlying causal reasoning strategies.

\subsection{The Method of Difference}

As we have seen, both the method of agreement and the method of concomitant variation help to make sense of many of Semmelweis's arguments, especially of his neglected numerical tables. However, from the point of view of justification, both methods are clearly defeasible, and we have seen that Mill judged the method of agreement to be an "inferior resource" to the method of difference. ${ }^{31}$ Let us then turn to the method of difference, which Mill believed to be uniquely reliable:

It $[\ldots]$ appears to be by the Method of Difference alone that we can ever, in the way of direct experience, arrive with certainty at causes. ${ }^{32}$

\footnotetext{
${ }^{28}$ Mill (1843), p. 472; III.VIII. $\$ 6$.

${ }^{29} \mathrm{I}$ am grateful to an anonymous referee for drawing my attention to this point.

${ }^{30}$ See Semmelweis (1861), p. 12.

${ }^{31}$ See the quotation from Mill on p. 8 .

${ }^{32}$ Mill (1843), p. 459; III.VIII.§3.
} 
The method of difference is similar to the method of agreement, but it imposes much more stringent criteria on the kinds of instances we are to compare:

If an instance in which the phenomenon under investigation occurs, and an instance in which it does not occur, have every circumstance save one in common, that one occurring only in the former; the circumstance in which alone the two instances differ, is the effect, or cause, or a necessary part of the cause, of the phenomenon. ${ }^{33}$

The method of difference captures a basic notion underlying at least one flavor of robust scientific methodology: Vary only one factor at a time to determine its causal role.

It hardly needs saying that much work is required to flesh out this intuition if it is supposed to do any real work. In particular, an account needs to be given of why we should ever judge two instances to differ in only one circumstance. (Mill suggests that the fact of artificial intervention provides such a reason. ${ }^{34}$ ) For now, however, I will focus only on the historical evidence which suggests that Semmelweis made conscious use of something like the method of difference, and that he did so in full awareness of the method's logic and force.

It is easy enough to retell Semmelweis's key clinical intervention as an application of the method of difference. Semmelweis had the suspicion that the reason for the high incidence of childbed fever in the first division was that doctors and medical students transported cadaverous matter from autopsies to the pregnant women they examined, and that the cadaverous matter in some way caused the disease. He mandated a hand-washing regime for those performing autopsies, and thereby achieved a striking reduction in the incidence of the disease. So in effect, Semmelweis had created two groups for (longitudinal) comparison: an "experimental" group (all the patients who were exposed to the cadaverous matter from autopsies) and a "control" group (all the patients who were not exposed to the cadaverous matter but otherwise treated the same). Since the disease occurred in the experimental group but not in the longitudinal control group, the causal role of cadaverous matter was established according to the method of difference.

Having retold Semmelweis's key inference in this mold, it is only right to note that mere plausibility does not offer strong reasons for preferring one methodological reconstruction over another: What specific reasons do we have for believing

\footnotetext{
${ }^{33}$ Mill (1843), p. 455; III.VIII. $\$ 2$.

${ }^{34}$ Mill (1843), p. 457; III.VIII.§3.
} 
that Semmelweis actually thought in terms of the method of difference? There are two pieces of evidence to consider.

First, Semmelweis's own description of his methodology is quite specific:

I assumed that the cause of the greater mortality rate was cadaverous particles adhering to the hands of examining obstetricians. I removed this cause by chlorine washings. Consequently, mortality in the first clinic fell below that of the second. I therefore concluded that cadaverous matter adhering to the hands of the physicians was, in reality, the cause of the increased mortality rate in the first clinic. ${ }^{35}$

This may not yet suffice to show that Semmelweis is conscious of the conceptual background of the method he is using. After all, he does not describe a general methodology in the abstract, but argues in terms of the concrete problem at hand. However, in the very next paragraph, Semmelweis goes on to assure the reader that, just as Mill's method requires it, the instances he is comparing have "every circumstance save one in common":

Since the chlorine washings were instituted with such dramatic success, not even the smallest additional changes in the procedures of the first clinic were adopted to which the decline in mortality could be even partially attributed. ${ }^{36}$

This is the second piece of evidence that strongly supports the view that Semmelweis did indeed think about his methodology in terms of varying one factor while alternative causes are controlled, so as to demonstrate the test factor's causal role. In the Etiology, much of the weight of the argument is again carried by numerical tables, which underpin the claim that the mortality rates between the two longitudinally compared groups differed as claimed. ${ }^{37}$

\footnotetext{
35“Ich habe vorausgesetzt, dass die an der untersuchenden Hand des Geburtshelfers klebenden Cadavertheile die Ursache der grösseren Sterblichkeit an der ersten Gebärklinik sei; ich habe diese Ursache durch die Einführung der Chlorwaschungen entfernt. Der Erfolg war, dass die Sterblichkeit an der ersten Gebärklinik in die Grenzen eingeengt wurde, innerhalb welcher sie auch an der zweiten vorgekommen ist, wie die oben angeführten Zahlen zeigen. Es ist also der Schluss, dass die an der Hand klebenden Cadavertheile in Wirklichkeit das Plus der Sterblichkeit an der ersten Gebärklinik hervorgebracht haben, auch ein berechtigter" (Semmelweis, 1861, p. 58, or Semmelweis, 1983, p. 92).

36"Seit die Chlorwaschungen mit so auffallend günstigem Erfolge in Gebrauch gezogen wurden, wurde nicht die geringste Veränderung in den Verhältnissen der ersten Gebärklinik vorgenommen, welcher man einen Antheil an der Verminderung der Sterblichkeit zuschreiben könnte" (Semmelweis, 1861, p. 58, or Semmelweis, 1983, p. 92).

${ }^{37}$ See table 15 and following in Semmelweis (1861), including one unlabeled table on p. 56, and tables 5 to 8 in Semmelweis (1983).
} 


\section{From causal to mechanistic knowledge}

The arguments of the preceding section strongly suggest that Mill's methods provide an adequate description of many or most of Semmelweis's inferences. However, it may be objected that Mill's methods leave us short of our inferential ambitions. For depending on how precisely we construe Semmelweis's application of the method of difference, his results are either not as informative, or else not as well founded, as is commonly assumed.

If we take Semmelweis merely to demonstrate that hand-washing is an effective means by which to reduce the incidence of childbed fever, then his results are reliable to the extent that the method of difference is reliable: Semmelweis intervened on the relevant causal variable (hand-washing) and observed the relevant effect (a reduction in the incidence of childbed fever), and he took care to establish that no alternative causal pathway was operative to confound his results. Thus, the method of difference establishes the causal role of hand-washing quite securely. But this is something less than the discovery concerning the causal role of cadaverous matter for which we celebrate Semmelweis, and which he himself believed to have made. On this interpretation, then, Semmelweis's findings are reliable, but in theoretical terms not very substantive.

On the other hand, if we take Semmelweis to have shown that cadaverous matter is the cause of childbed fever, the situation is reversed: We get a substantive result at the price of reliability. To see why this is so, let us assume for argument's sake that the chlorinated lime solution cures childbed fever, even if it is applied only in small quantities. Semmelweis's experimental results would still hold: Hand-washing would reduce the incidence of the disease. But the removal of cadaverous matter from the hands of the physicians would be a mere epiphenomenon of the true causal pathway, which involves the transfer of curative chlorinated lime solution from physicians to patients.

We must conclude that Semmelweis's results do not speak directly to the causal role of cadaverous matter: His results concerning the effectiveness of hand-washing are solid, but the details of his pathophysiological hypothesis are underdetermined.

Peter Lipton regarded this as a general problem for Mill's methods. ${ }^{38}$ We may accept that Mill's method of difference licenses the inference from observed differences to causal roles (given a deterministic system, the exclusion of confounders, and so on). But oftentimes we are not inferring the causal role of an observed dif-

\footnotetext{
${ }^{38}$ See Lipton (2004), pp. 126-128.
} 
ference, but of a difference which is itself only inferred. In Semmelweis's time, the absence or presence of cadaverous matter adhering to the hands of physicians was unobservable, and hence it constituted such an inferred difference. This seems to block the straightforward application of the method of difference to the question of whether cadaverous matter causes childbed fever. Lipton argues that there is a reason why we nevertheless believe that Semmelweis's clinical intervention confirmed his pathophysiological hypothesis: The unobserved difference (cadaverous matter adhering or not adhering to the hands of physicians) would be a good explanation of the observed difference (high or low mortality from childbed fever) if it did exist. Thus, to make Mill's methods do any real work, Lipton argues, we need to supplement them with explanatory considerations. ${ }^{39}$

However, close consideration of the historical sources again suggests that the philosophical debate has neglected, to its detriment, historical facts.

First, it is not strictly true that cadaverous matter was unobservable to Semmelweis. He noted repeatedly that the sense of smell allowed him to determine whether chlorine washings had been effective. ${ }^{40}$ In other words, the sense of smell provided Semmelweis with a diagnostic criterion for the presence or absence of cadaverous matter. He also noted that the quantities of cadaverous matter that were relevant to his investigation were so minuscule that only the sense of smell could be used to diagnose their presence. ${ }^{41}$ Thus, despite the fact that the cadaverous matter is not observable to human eyes, Semmelweis had some causal access to it. This does not solve the underdetermination problem I introduced above, but it speaks against the notion that Semmelweis was relying on an unobservable difference which was inferred only on explanatory grounds. Given more reliable diagnostic criteria, Mill's method of difference could in principle be applied rigorously to the problem.

Second, and more importantly, Semmelweis's investigations did not stop with his clinical intervention. Philosophers of science have tried to explain why Semmelweis's clinical results speak directly to the truth of his pathophysiological hypothesis. This is where reconstructions of Semmelweis's work in terms of the hypothetico-deductive model of confirmation, or in terms of inference to the best explanation, seem most attractive. In Semmelweis's own argument, however, the gap between clinical results and pathophysiological hypothesis is bridged by animal experiments.

\footnotetext{
${ }^{39}$ Alexander Bird makes a similar argument, see Bird (2010), p. 351.

${ }^{40}$ See for instance Semmelweis (1861), p. 54; the same is noted by one of Semmelweis's correspondents on p. 287. See also Semmelweis (1983), p. 88 and p. 177.

${ }^{41}$ Semmelweis (1861), p. 339; the passage is not included in Carter's translation.
} 
Semmelweis writes that he performed animal experiments in order "to confirm my views directly". ${ }^{42}$ His choice of words - the distinction between direct and indirect support - is appropriate. The success of the clinical intervention certainly served to make Semmelweis's pathophysiological hypothesis plausible, but this is only indirect support for the reasons outlined above. The open question was whether cadaverous matter is in fact capable of entering the organism's blood stream from the uterus, and whether it can induce pyemia such as is observed in childbed fever. Finding a direct answer to this question is the goal of Semmelweis's animal experiments.

The experiments are presented in the Etiology on pp. 76-80, but they were also part of one of the earliest published accounts of Semmelweis's findings. ${ }^{43}$ Semmelweis reports a total of nine animal experiments in which the uteri of rabbits were treated with various fluids such as exudate from endometritis or pus from abscesses. The animals died after developing pathological changes which closely mirrored those of puerperal fever. ${ }^{44}$

There is every reason to think that Semmelweis's experiments were not conducted particularly carefully. Unlike the clinical investigation, the animal experiments seem haphazard. Semmelweis experimented on only a small number of animals, and he changed his methodology several times. For instance, he began by introducing substances into the uteri of rabbits by brush, but then switched to syringes so as to avoid damaging the uterine tissue. He also used a variety of substances such as pus and exudate unsystematically. As far as we know, no control experiments were performed. Moreover, Semmelweis's pathophysiological hypothesis assumed that minuscule amounts of cadaverous matter were transmitted from physicians to patients, but in the animal experiments large amounts of deleterious substances were inserted into the animals' uteri. Semmelweis's opponent Friedrich Wilhelm Scanzoni thought it was a trivial finding that such crude interventions will cause pyemia in animals. ${ }^{45}$ This is certainly a reasonable objection. I do not wish to claim that Semmelweis's animal experiments were decisive - they were not, and reasonable people could doubt Semmelweis's pathophysio-

\footnotetext{
42، Um meine Ansichten einer direkten Prüfung zu unterziehen, hielt ich Versuche an Thieren für nöthig [...].” See p. 76 in Semmelweis (1861) and p. 105 in Semmelweis (1983).

${ }^{43}$ See Joseph Skoda's paper in von Győry (1905), pp. 36-45.

${ }^{44}$ Semmelweis (1861), p. 80.

${ }^{45}$ Scanzoni's remarks are in Vierteljahrschrift für die praktische Heilkunde, Vol. 7(2), 1850, in the section Literarischer Anzeiger, p. 25-33. Semmelweis (1861) discusses Scanzoni at length, beginning on p. 315 .
} 
logical hypothesis. Nevertheless, it seems clear that the animal experiments were intended to close a gap in what could be learned from clinical experiments alone. ${ }^{46}$

The line of evidence concerned with animal experiments is usefully considered mechanistic in the sense of the past decade's literature on that subject. It is not necessary to commit to any particular flavor of the mechanistic approach. ${ }^{47}$ All of them understand mechanisms roughly as "entities" (Machamer, Darden and Craver) or "component parts" (Bechtel) which interact in well defined ways. We have a mechanistic explanation of a phenomenon if we can show how it was brought about by accepted entities and accepted interactions which are organized in a continuous chain. In Semmelweis's animal experiments, questions of a mechanistic nature took center stage - for instance, the question of whether the uteri of healthy pregnant women even have abrasions through which cadaverous matter could enter the blood stream. This is why Semmelweis stopped using a brush, whose hairs might cause wounds, and started using a syringe to introduce substances into the animals' uteri: The mechanism had to operate in the absence of experimenter-induced uterine wounds. Nevertheless, Semmelweis's opponents remained doubtful that the necessary path of entry from the uterus into the blood stream existed in otherwise healthy patients. ${ }^{48}$ Special emphasis was further placed on whether a particular type of interaction existed: cadaverous matter causing pyemia. These are exactly the mechanistic questions left unanswered if the clinical data is considered in isolation. $^{49}$

At least one of Semmelweis's contemporaries believed the animal experiments to be the clinching piece of evidence. Joseph Skoda, in one of the first public

\footnotetext{
${ }^{46}$ The clinical information offered some limited support for the pathophysiological hypothesis: In 1847, Semmelweis's colleague Kolletschka cut himself during a dissection, experienced similar symptoms as women who died from chlidbed fever (which we would now recognize as sepsis) and died. Semmelweis claimed that Kolletschka's death was an important clue to the cadaverousmatter-hypothesis (Semmelweis, 1861, p. 52 and Semmelweis, 1983, p. 87-88). I am grateful to an anonymous referee for emphasizing this link between the clinical data and the pathophysiological hypothesis.

${ }^{47}$ See Glennan (1996), Machamer et al. (2000) and Bechtel (2006).

${ }^{48}$ See Bernard Seyfert's arguments against Semmelweis immediately following those of Scanzoni, cited in footnote 45 , p. 34-36.

${ }^{49}$ Russo and Williamson (2007), p. 163, argue that the mechanistic question could only be answered with the advent of the germ theory of disease. I think this is overly pessimistic: Whether a particular causal process constitutes a proper mechanism will depend on the accepted bottoming-out activities (Machamer et al., 2000, p. 13-14). Today, a full mechanistic explanation of childbed fever would ask for detailed information about how particular bacteria enter the organism and activate the immune system, down to interactions between cell-surface receptors. In 1850, the fact that "cadaverous matter" can induce pyemia - if established well - might have been a perfectly acceptable bottoming-out activity.
} 
communications of Semmelweis's findings in 1849, suggests a long list of further statistical data that could be obtained to test Semmelweis's claims - for example, statistics over longer periods of time and from other hospitals. But of the animal experiments Skoda says:

If they succeeded, the solution of the other tasks was of lesser importance..$^{50}$

Skoda's view that the animal experiments can clinch the matter makes sense if we understand their role in fleshing out the pathophysiological mechanism underlying the clinical data.

Like the numerical tables discussed above, the experiments were given short shrift by many authors. Hempel and Lipton do not mention them at all; and in Carter's translation, the experiments are omitted save for a summary (p. 105). The omission of the animal experiments has made it impossible to appreciate the full evidential force of Semmelweis's arguments: Clinical data and animal experiments are complementary, the former proving the effectiveness of the hand-washing intervention, the latter supporting the pathophysiological mechanism.

\section{Conclusions}

I have argued that there exists a largely untold methodological story behind Semmelweis's abundant numerical tables. The tables were omitted from widely available editions of the Etiology, and philosophers of science have mostly ignored them. A reconstruction of the tables in terms of Mill's methods of causal inference forms the basis of my account of Semmelweis's clinical investigations.

Moreover, I have argued that methodological reconstructions of Semmelweis's work have generally tried to establish too much on the basis of clinical findings alone. Upon closer consideration, the empirical support for Semmelweis's proposed pathophysiological mechanism rests in large part on his likewise neglected animal experiments.

The present paper is mainly an argument for the descriptive adequacy of a reconstruction of Semmelweis's work in terms of causal reasoning and mechanisms. It remains for a subsequent paper to compare and contrast the philosophical virtues of the various accounts of Semmelweis's work.

\footnotetext{
50 "Wenn diese gelangen, war die Lösung der übrigen Aufgaben von geringerer Bedeutung" (von Győry, 1905, p. 42).
} 


\section{Acknowledgements}

I am indebted to Tim Räz, Kärin Nickelsen and two anonymous referees for helpful comments on earlier drafts of the paper. I also presented a very early version of this material at the Progress in Medicine conference in Bristol, April 2010, and a more advanced version at the Congress of Logic, Methodology, and Philosophy of Science in Nancy, July 2011. I thank those audiences for their helpful comments and suggestions.

\section{References}

Bechtel, W. 2006. Discovering cell mechanisms: The creation of modern cell biology. Cambridge University Press.

Bird, A. 2010. Eliminative abduction: examples from medicine. Studies in History and Philosophy of Science 41: 345-352.

Friendly, M. 2008. A brief history of data visualization. In C. H. Chen, W. Härdle, and A. Unwin, eds., Handbook of Data Visualization. Springer, pp. 15-56.

Funkhouser, H. G. 1937. Historical development of the graphical representation of statistical data. Osiris 3: 269-404.

Gillies, D. 2005. Hempelian and Kuhnian approaches in the philosophy of medicine: the Semmelweis case. Studies in History and Philosophy of Biological and Biomedical Sciences 36(1): 159-181.

Glennan, S. 1996. Mechanisms and the Nature of Causation. Erkenntnis 44(1): $49-71$.

Hempel, C. G. 1966. Philosophy of Natural Science. Prentice Hall.

Lesky, E. 1964. Ignaz Philipp Semmelweis und die Wiener Medizinische Schule. Graz, Wien: H. Böhlau.

Lipton, P. 2004. Inference to the Best Explanation. Routledge.

Lumpe, E. 1845. Die Leistungen der neuesten Zeit in der Gynaekologie. Zeitschrift der k. k. Gesellschaft der Aerzte zu Wien 1(2): 341-371.

Machamer, P., L. Darden, and C. F. Craver. 2000. Thinking about Mechanisms. Philosophy of Science 67(1): 1-25. 
Mill, J. S. 1843. A System of Logic. London: John W. Parker.

Murphy, T. D. 1981. Medical knowledge and statistical methods in early nineteenth-century France. Medical History 25(3): 301-19.

Nickelsen, K. and G. Graßhoff. 2011. In pursuit of formaldehyde: Causally explanatory models and falsification. Studies in History and Philosophy of Biological and Biomedical Sciences 42(3): 297-305.

Porter, R. 1999. The Greatest Benefit to Mankind: A Medical History of Humanity. W. W. Norton.

Russo, F. and J. Williamson. 2007. Interpreting Causality in the Health Sciences. International Studies in the Philosophy of Science 21(2): 157-170.

Semmelweis, I. P. 1861. Die Aetiologie, der Begriff und die Prophylaxis des Kindbettfiebers. Pest, Wien and Leipzig: C. A. Hartleben.

2. 1941. The etiology, the concept and the prophylaxis of childbed fever. Medical Classics 5(5-8): 339-478; 481-589; 591-715; 719-773. Translated by Frank P. Murphy.

1983. The etiology, concept, and prophylaxis of childbed fever. Madison: University of Wisconsin Press. Translated and edited by K. Codell Carter.

Tröhler, U. 2000. To Improve the Evidence of Medicine: The 18th Century British Origins of a Critical Approach. Edinburgh: Royal College of Physicians.

von Győry, T. 1905. Semmelweis' gesammelte Werke. Jena: Gustav Fischer.

Zweifel, P. 1912. Ign. Phil. Semmelweis: Ätiologie, Begriff und Prophylaxis des Kindbettfiebers (1861). Leipzig: Johann Ambrosius Barth. 


\section{Figures}

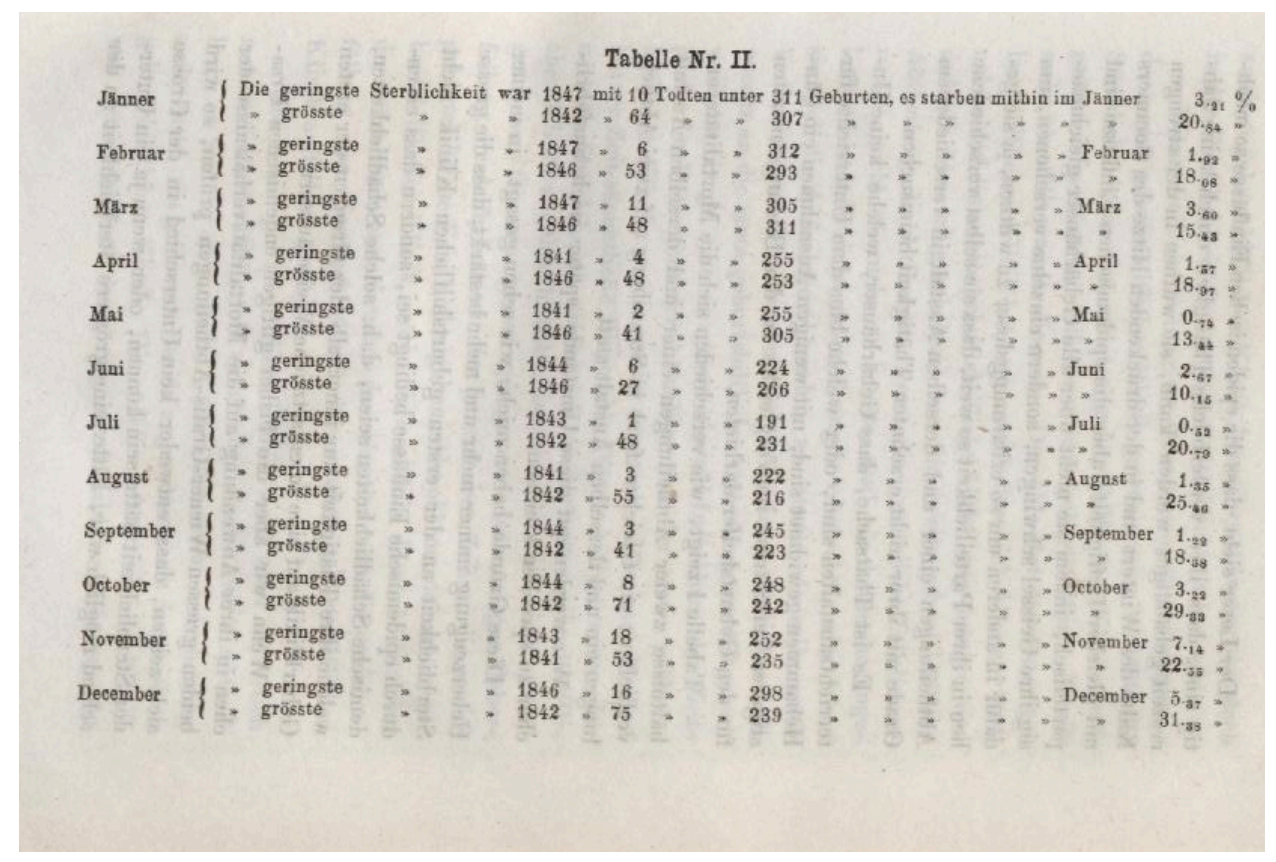

Figure 1. Semmelweis's second table. It shows that extremes of high and low mortality from childbed fever occur in every month of the year, which leads Semmelweis to exclude the time of year as a cause of childbed fever. This may be understood as an application of Mill's method of agreement, as explained in the text. (All tables are from the digitized copy of Semmelweis (1861) in the Staatsbibliothek zu Berlin. Accessed through Deutsches Textarchiv, Berlin-Brandenburgische Akademie der Wissenschaften, 2011.) 


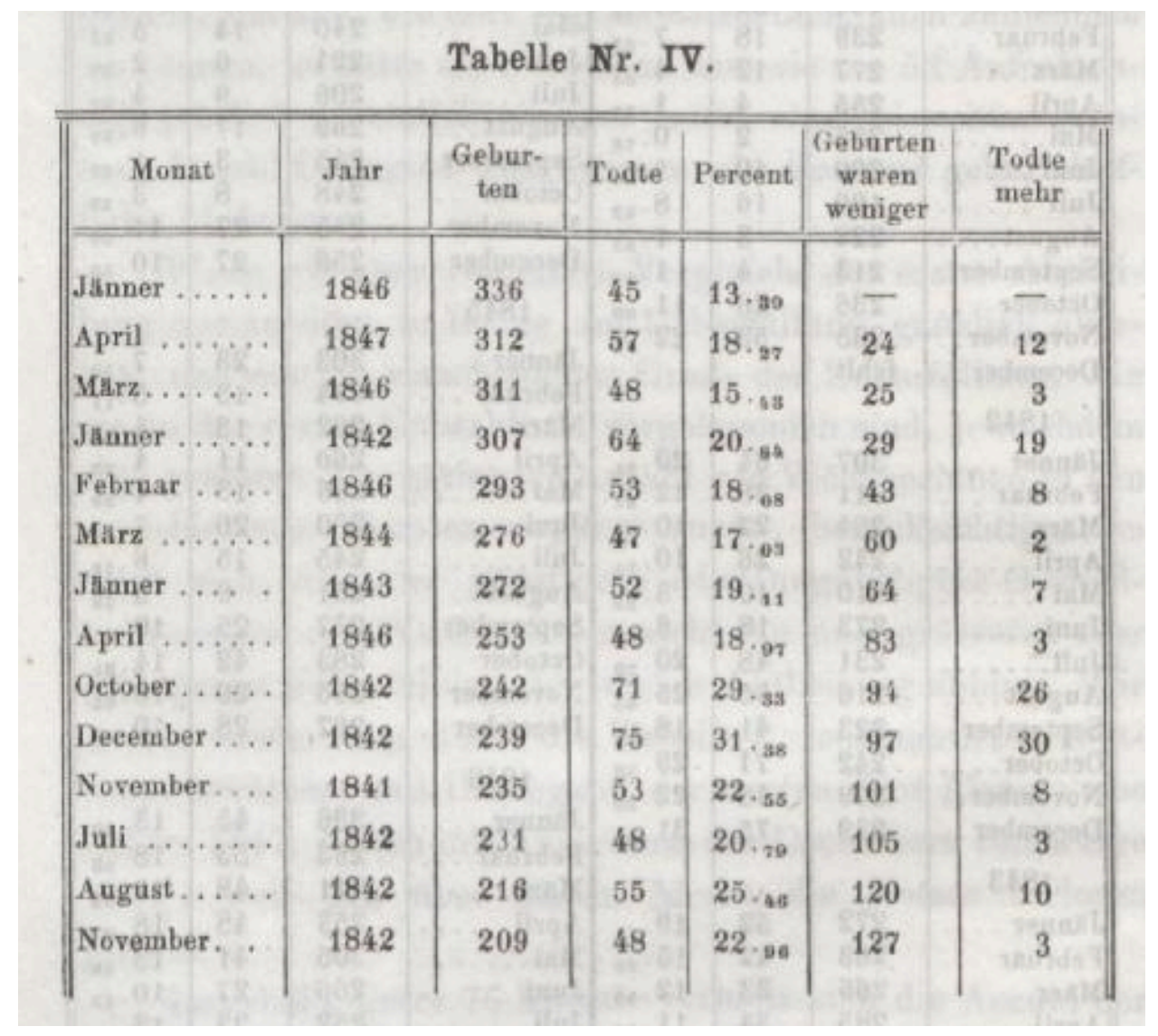

Figure 2. Semmelweis's fourth table, which was omitted from some of the most widely available editions of the Etiology. Semmelweis is arguing that crowding and mortality do not vary concomitantly. First column: month; second column: year; third column: number of births; fourth column: absolute mortality; fifth column: relative mortality; sixth column: difference in number of births relative to baseline (January 1846); seventh column: difference in number of deaths relative to baseline. Note especially columns six and seven: As the number of births decreases, the number of deaths merely fluctuates. In other words, no concomitant variation is observed. 


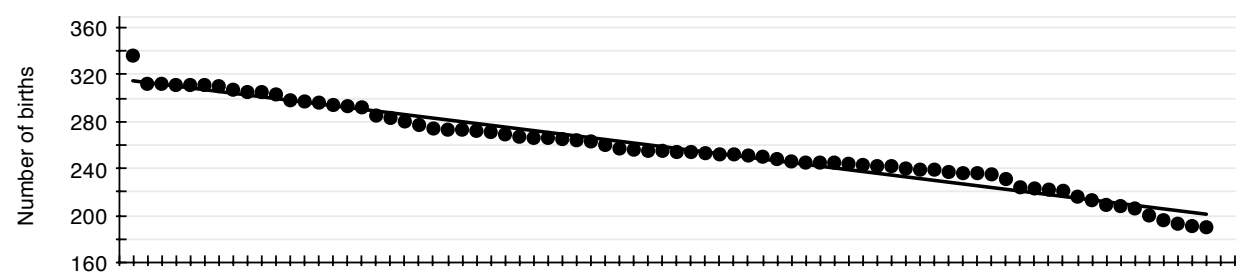

76 months from 1841 to 1847 , ordered by decreasing number of births

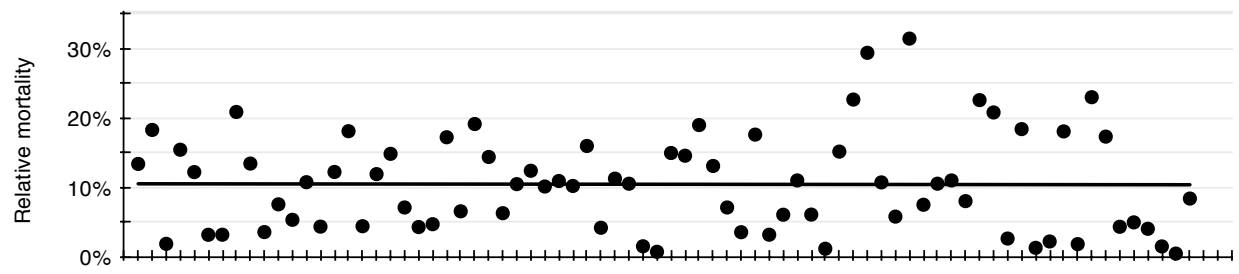

76 months from 1841 to 1847 , ordered by decreasing number of births

Figure 3. A graphical representation of Semmelweis's application of the method of concomitant variation to investigate the relationship between crowding and mortality. Top panel: Semmelweis's 76 months (from his third table) are ordered by decreasing number of births, which is taken as a proxy for decreasing crowding. Bottom panel: Relative mortality does not vary concomitantly with decreasing crowding, but instead merely fluctuates around the average relative mortality of $10 \%$. Lacking a graphical means of representation, Semmelweis tried to convey the same result in tabular form. 


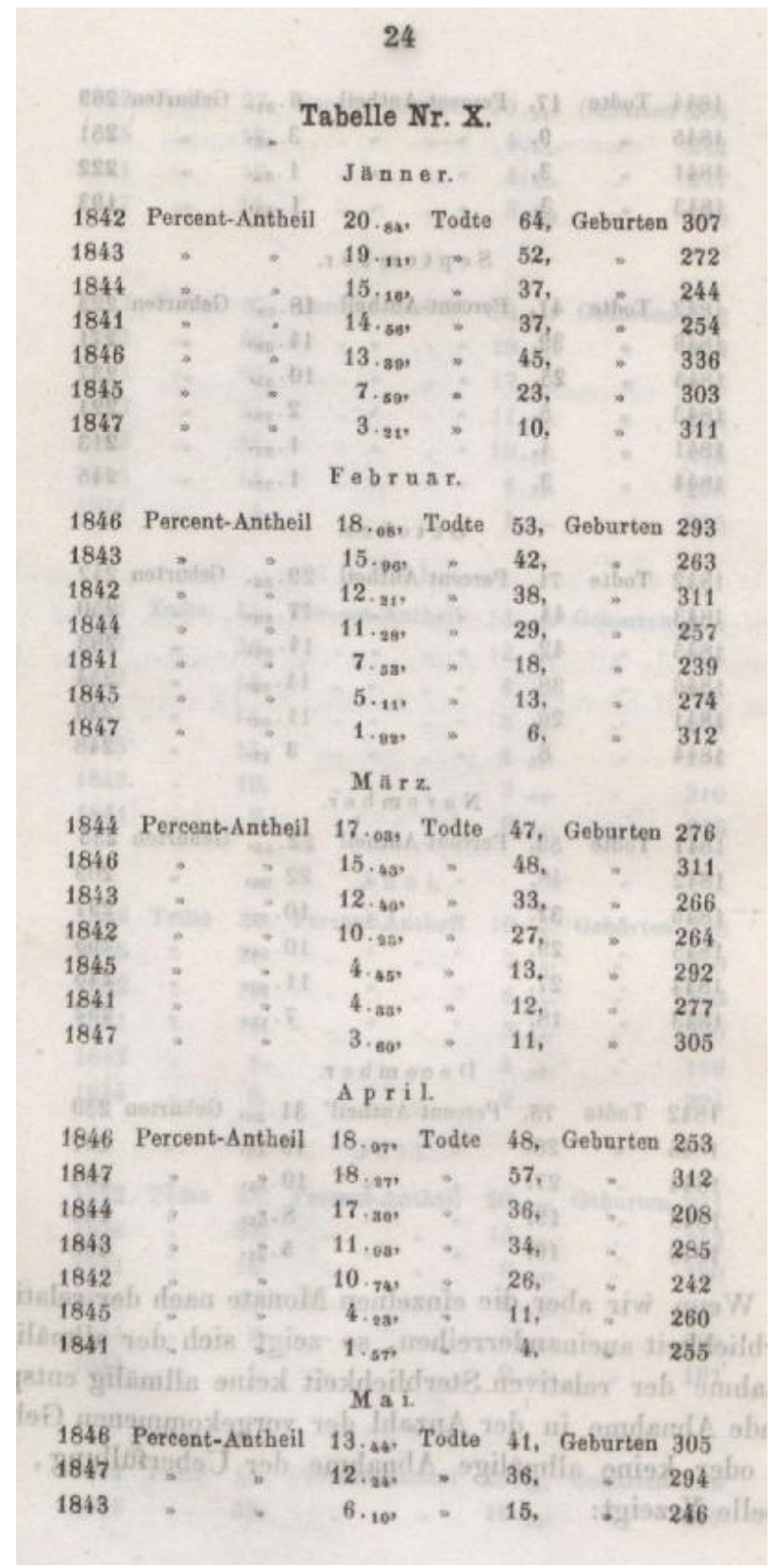

Figure 4. Semmelweis's tenth table. Semmelweis is considering the possibility that crowding may influence childbed fever only during certain months of the year. He therefore analyzes his data by months, here arranging the years for each month by decreasing relative mortality. See text for details. 


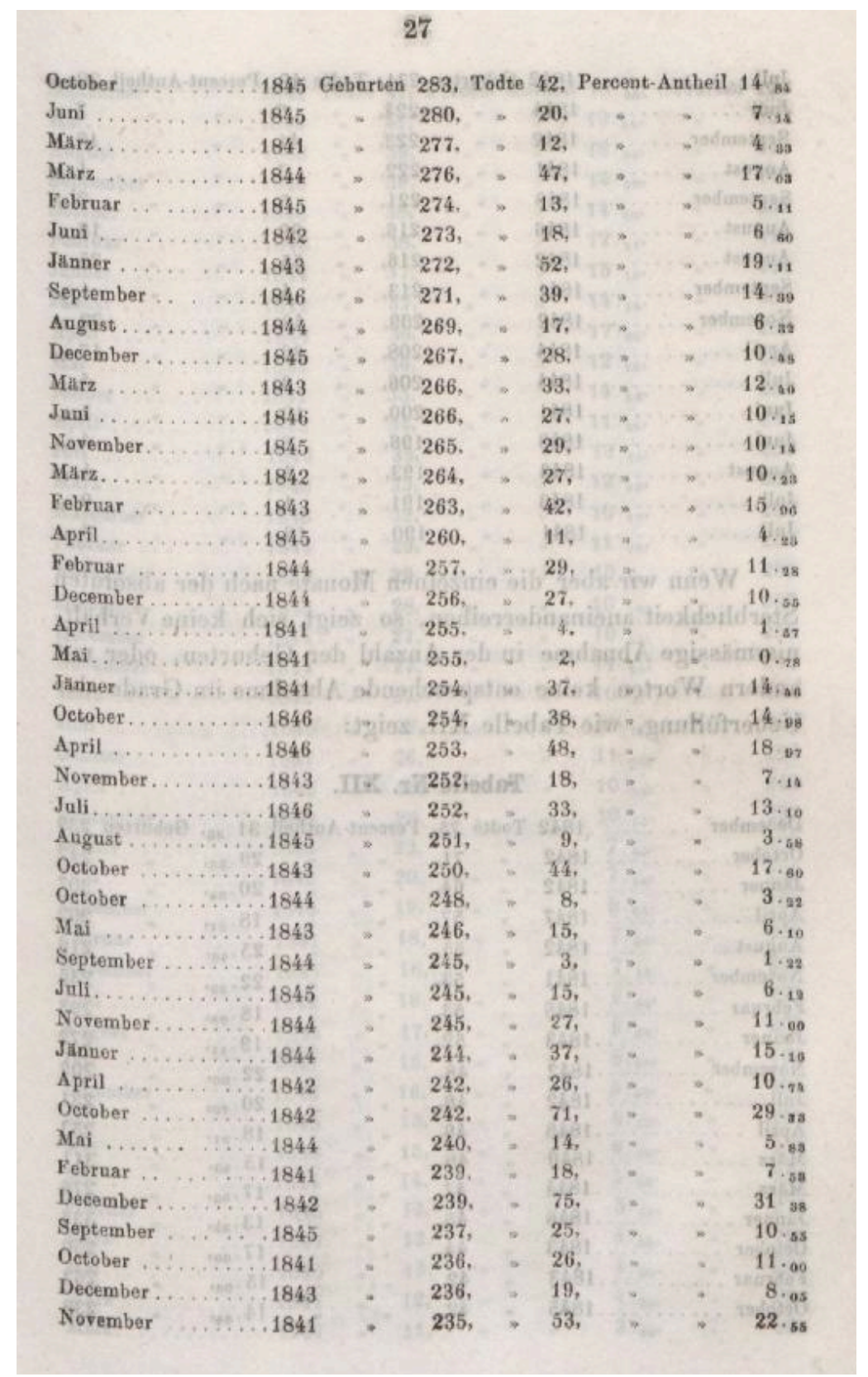

Figure 5. Semmelweis's eleventh table. The table is arranged by decreasing number of births. Mortality does not vary concomitantly, but fluctuates. This is the second page of the table. 